\title{
The Evolution of Devices and Techniques in Endovascular Stroke Therapy
}

\author{
Devin V. Bageac • Blake S. Gershon • Reade A. De Leacy \\ Cerebrovascular Center, Department of Neurosurgery, Mount Sinai, New York, NY, USA
}

Author for correspondence: Reade A. De Leacy, Cerebrovascular Center, Department of Neurosurgery, Mount Sinai, New York, NY, USA. Email: reade.deleacy@mountsinai.org

Doi: https://doi.org/10.36255/exonpublications.stroke.devicesandtechniques.2021

\begin{abstract}
This chapter discusses the evolution of devices and techniques in endovascular stroke therapy, beginning with the development of effective intra-arterial thrombolysis in the late 1990s. We discuss the subsequent rise of early mechanical devices such as the Merci Retriever and Penumbra System, which, despite culminating in a series of failed trials in 2013, set the stage for the modern thrombectomy era. These first-generation devices gave way to the stent retriever, which would change the standard of care for acute large vessel occlusion stroke following a series of landmark trials in 2015. Finally, we discuss the more recent establishment of aspiration thrombectomy as an alternative to stent retrievers, as well as current investigations into novel devices and techniques that might further improve patient outcomes. Throughout, attention is paid to the regulatory landscape and evidentiary standards that shaped the field during its development in order to better understand how lessons from this history can guide future studies.
\end{abstract}

Keywords: endovascular stroke; intraarterial thrombolyisis; Merci retriever; penumbra system; stent retriever

In: Stroke. Dehkharghani S (Editor). Exon Publications, Brisbane, Australia. ISBN: 978-0-6450017-6-1; Doi: https://doi.org/10.36255/exonpublications.stroke.2021

Copyright: The Authors.

License: This open access article is licenced under Creative Commons Attribution-NonCommercial 4.0 International (CC BY-NC 4.0) https://creativecommons.org/licenses/by-nc/4.0/ 


\section{INTRODUCTION}

The past three decades have seen a revolution in the treatment of acute ischemic stroke caused by large vessel occlusion (LVO). Beginning in the 1990s with intraarterial (IA) thrombolysis, the field of endovascular stroke intervention (ESI) has cycled rapidly through multiple generations of devices and techniques that have established mechanical thrombectomy as the standard of care in select patients suffering from acute large vessel occlusive stroke. Progress has been incremental, as techniques and devices are modified and evaluated based on standards set by the previous generation. This chapter aims to outline the evolution of modern ESI, while highlighting the continuity between technological advancements and the factors informing how new techniques are evaluated and adopted.

\section{INTRAARTERIAL THROMBOLYSIS}

Investigations into endovascular stroke intervention began over a decade before intravenous (IV) thrombolysis became the standard of care in select patients suffering from acute ischemic stroke. In 1983, Zeumer et al. were the first to perform basilar thrombolysis via catheter injection of streptokinase in five patients, reporting exceptional outcomes when compared to the known natural history of the disease (1). The majority of early thrombolysis trials, however, would focus on IV as opposed to IA administration, and culminated in the pivotal 1995 trial that led to FDA approval of IV tissue plasminogen activator (tPA) for the treatment of acute ischemic stroke within 3 hours of symptoms onset (2).

Despite this leap forward, IV tPA administration had significant limitations that continued to spark interest in endovascular stroke therapy. The most significant limitation was the narrow 3-hour time window for the initiation of therapy. Between 1995 and 1998, six randomized trials failed to show an overall benefit for IV thrombolytic therapy initiated within 6 hours of stroke onset, and it would be nearly 15 years before the tPA window saw a modest increase of 1.5 hours in select patients (3-9). Aside from the issue of time-to-administration, it also appeared that IV tPA was relatively ineffective at recanalizing large vessel occlusions, as evidence from the unpublished Thrombolytic Therapy of Acute Thrombotic/Thromboembolic Stroke Study (TTATTS), which suggested recanalization rates of no more than 30\% for tPA-treated middle cerebral artery (MCA) occlusions (10).

In hopes of addressing these shortcomings, Drs. Anthony Furlan, Gregory Del Zoppo, Randall Higashida, and Michael Pessin made a proposition to Abbott Laboratories that prompted the company to fund a large IA thrombolysis trial aimed at obtaining FDA approval of their new thrombolytic agent, recombinant pro-urokinase (r-proUK), for the endovascular treatment of MCA occlusions within 6 hours of onset (11). Two studies resulted from this, known as the Prolyse in Acute Cerebral Thromboembolism (PROACT) trials, which were conducted between 1994 and 1998.

PROACT was a randomized control trial (RCT) designed to demonstrate the safety and recanalization efficacy of IA r-proUK compared to IA saline in the treatment of MCA occlusion within 6 hours of stroke onset (12). The injection technique 
required the proceduralist to embed a microcatheter ( $<3$ French) into the body of the thrombus, followed by the infusion of $9 \mathrm{mg}$ of r-proUK over the course of two hours. During the recruitment period, IV tPA was approved by the FDA, and thus the study was terminated early due to ethical concerns regarding the use of an evidently inferior placebo group. Nonetheless, PROACT was able to report results on 46 randomized cases, which showed that IA r-proUK was significantly more likely to result in partial or complete recanalization $(57.7 \%$ vs. $14.3 \%$; $=.017)$. The vast majority of patients were treated beyond the three-hour IV tPA window.

Encouraged by the results of PROACT, Abbott Laboratories agreed to fund PROACT-II, a phase III trial that compared the safety and clinical efficacy of IA r-proUK plus IV heparin vs. IV heparin alone in patients with MCA occlusion strokes within 6 hours of onset (13). This study followed the same technique established in PROACT, and enrolled a total of 180 patients. The primary outcome measure was defined as slight or no neurological impairment at 90 days post-procedure, corresponding to a modified Rakin Scale (mRS) score of 2 or less. In the final analysis, IA r-proUK resulted in a 15\% absolute increase in the rates of $m R S \leq 2$ outcomes ( $40 \%$ vs. $25 \% ; p=0.4$ ), with recanalization rates of $66 \%$ vs. $18 \%$ for the IV heparin control group $(\mathrm{p}<0.001)$. Intracranial hemorrhage with neurological deterioration within 24 hours occurred in $10 \%$ of r-proUK patients and $2 \%$ of control patients $(\mathrm{p}=0.06)$.

Despite these positive results, the FDA would not go on to approve r-proUK for IA stroke therapy, and to this day, the PROACT trials stand as the only randomized, controlled trials of IA thrombolysis to show a statistically significant clinical benefit. While other IA studies have demonstrated trends towards improved outcomes, they have been inadequately powered to show statistically significant improvement (14). Despite these smaller failed trials, meta-analysis of combined data in 395 patients from five trials provides a strong indication of statistically significant good (odds ratio [OR[, 2.05; 95\% confidence interval [CI], 1.33 to 3.14; $\mathrm{p}=0.001)$ and excellent outcomes (OR, 2.14; $95 \% \mathrm{CI}, 1.31$ to 3.51; $\mathrm{p}=0.003)$.

Though IA thrombolysis never entered widespread use as first-line therapy for stroke intervention, PROACT-II would set the standard against which future attempts at endovascular stroke intervention would be judged.

\section{DAWN OF THE DEVICE ERA: THE MERCI RETRIEVER}

Encouraged by the prospect of IA stoke therapy as demonstrated by the PROACT trials, a flurry of new devices emerged with the goal of achieving cerebral reperfusion without the hemorrhage risks inherent to pharmacologic thrombolytics. Early attempts included lasers, microsnares, and rheolytic thrombectomy systems, all of which failed to demonstrate adequate safety and efficacy profiles (15). But among these early devices was the Concentric Thrombus Retriever (Concentric Medical, Mountain View, CA), later renamed the Mechanical Embolus Removal in Cerebral Ischemia (Merci) Retriever, which would become the first clot retrieval device to achieve regular use in the United States.

The initial design patent for the Merci Retriever belonged to Dr Y. Pierre Gobin, and was cleared by the FDA for use in the retrieval of foreign bodies misplaced 
during interventional radiological procedures in the cerebral, peripheral and coronary vascular systems (510(k) Number K003410). The retriever consisted of a corkscrew shaped nitinol wire of five helical loops that gradually decreased in diameter (Figure 1). During use, the device was unsheathed from a catheter within a foreign body in order to ensnare and remove the target by retrieval through a guide catheter. Though the device was never used widely, Concentric Medical (Mountain View, CA) would go on to acquire the license for the device and pursue clearance for a new indication: the restoration of neurovascular blood flow by thrombus removal in patients experiencing ischemic stroke.

In the United States, medical device regulations differ significantly from drug regulations in ways that were fundamental to the viability of the Merci Retriever and other devices like it. While all drugs must go through a full approval processtypically necessitating large phase III trials - devices have the option of pursuing $510(\mathrm{k})$ clearance, for which they must only show that a device is sufficiently similar to one already on the market. In order to change the stated indication for a device, a $510(\mathrm{k})$ application can be submitted with data showing that it is safe and effective for the new intended use. To this end, the exact language of the indication sought for the Merci Retriever was critical. It did not state that the device was intended for the treatment of stroke per se (as this would require clinical outcomes data), but rather, for the restoration of blood flow by thrombus removal. As such, the data submitted to the FDA was only required to show that the device could achieve recanalization without significant safety events (16).

Thus, the single-arm MERCI Trial was conducted and reported results in 2005 (17). The study enrolled 153 patients and, while it did not contain a control group of its own, it compared recanalization rates using the Merci Retriever to those achieved in the control arm of PROACT-II. The procedure involved an IV bolus of

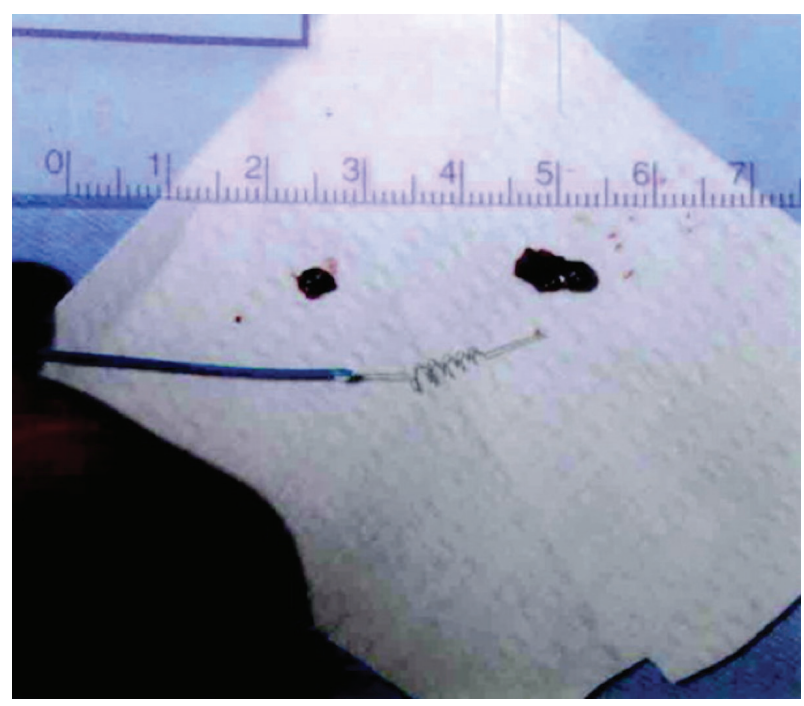

Figure 1. Photograph showing the Merci Retriever and 2 thrombi. Reproduced from Gobin et al. "MERCI 1" published in Stroke 2004. Reprinted with permission. 
$3000 \mathrm{U}$ of heparin, followed by standard femoral access using a balloon guide catheter (BGC). Next, a microcatheter was guided into the occluded vessel and passed beyond the thrombus. The Merci Retriever was then advanced through the microcatheter and 2 to 3 helical loops were deployed beyond the clot. The device was then retracted in order to contact the distal end of the clot, and the proximal loops were deployed within the thrombus. The BGC balloon was inflated, and five clockwise rotations were applied to the device to further ensnare the thrombus. Finally, the microcatheter, device, and ensnared thrombus, were withdrawn together into the BGC lumen under continuous aspiration. This procedure was repeated up to six times in the event of unsuccessful reperfusion (18). Descriptions of the reperfusion scales referred to in this chapter are available in Table 1.

Final analysis of the MERCI Trial showed that the device achieved recanalization (defined as Thrombolysis in Myocardial Infarction (TIMI) II or III flow in all treatable vessels) in 48\% of patients when the Merci Retriever was used alone, compared to $18 \%$ in the PROACT-II controls $(\mathrm{p}<0.0001)$. Clinically significant procedural complications occurred in $7 \%$ of patients, and only $28 \%$ went on to have a good neurologic outcome ( $\mathrm{mRS} \leq 2)$ at 90 days. Importantly, a significant direct relationship was demonstrated between successful recanalization and good 90-day outcomes ( $46 \%$ vs. $10 \%$; p < 0.0001 ).

Troublingly, however, mortality in the MERCI Trial was high (32\%), and over the course of the trial design modifications were introduced in order to address recurrent device fractures, which occurred in 11 of 153 cases (7\%). An FDA advisory panel expressed concerns about these issues, as well as the lack of a randomized control group. Nonetheless, the FDA granted clearance for the new indication (16).

\section{TABLE 1 Description of common reperfusion scales}

\begin{tabular}{|c|c|c|}
\hline TIMI & $\mathrm{TICl}$ & mTICI \\
\hline 0: Complete occlusion & 0: Complete occlusion & 0: Complete occlusion \\
\hline $\begin{array}{l}\text { 1: Flow beyond } \\
\text { occlusion but no } \\
\text { distal perfusion }\end{array}$ & 1: Penetration with minimal perfusion & $\begin{array}{l}\text { 1: Penetration with minimal } \\
\text { perfusion }\end{array}$ \\
\hline \multirow{2}{*}{$\begin{array}{l}\text { 2: Delayed flow } \\
\text { with sluggish or } \\
\text { incomplete filling } \\
\text { of distal branches }\end{array}$} & $\begin{array}{l}\text { 2a: Partial filling of }<2 / 3 \text { previously } \\
\text { occluded territory }\end{array}$ & $\begin{array}{l}\text { 2a: Partial filling of }<1 / 2 \text { previously } \\
\text { occluded territory }\end{array}$ \\
\hline & $\begin{array}{l}\text { 2b: Complete filling of previously } \\
\text { occluded territory, but filling is } \\
\text { slower than normal. }\end{array}$ & $\begin{array}{l}\text { 2b: Partial filling of }>1 / 2 \text { previously } \\
\text { occluded territory }\end{array}$ \\
\hline $\begin{array}{l}\text { 3: Normal flow filling } \\
\text { distal branches } \\
\text { (including M3/M4) }\end{array}$ & $\begin{array}{l}\text { 3: Complete perfusion without flow } \\
\text { defects }\end{array}$ & $\begin{array}{l}\text { 3: Complete perfusion without } \\
\text { flow defects }\end{array}$ \\
\hline
\end{tabular}

mTICI, modified Treatment in Cerebral Ischemia; TIMI, Thrombolysis in Myocardial Infarction; TICI, Thrombolysis in Cerebral Infarction 
One year later, Multi MERCI, a second single arm trial, would report prospective multi-center results using an updated version of the Merci Retriever in 111 patients with LVO stroke treated within 8 hours of symptom onset (19). Compared to the original MERCI Trial, treatment with the new Merci Retriever reported higher device-only recanalization rates (54\% vs. 48\%), better 90-day clinical outcome ( $\mathrm{mRS} \leq 2$ in $34 \%$ vs. $28 \%$ ), fewer clinically significant procedural complications (4.5\% vs. $7.1 \%$ ), and lower 90-day mortality (31\% vs. 44\%). Following the use of adjunctive techniques (clot disruption and IA thrombolysis), the final rate of successful recanalization was $68 \%$.

Largely as a result of the confidence instilled by these two studies, more than 10,000 Merci thrombectomies would be performed worldwide by 2010, and years would pass before randomized studies would be funded to evaluate the true efficacy of mechanical thrombectomy (11). Perhaps most importantly, the Merci devices would serve as the primary predicate devices for a litany of new $510(\mathrm{k})$ applications throughout the late 2000s and early 2010 s.

\section{THE PENUMBRA SYSTEM}

The most significant entrant into the immediate post-Merci world of thrombectomy devices was the Penumbra System (Penumbra Inc., Alameda, CA), which received 501(k) clearance in 2007 using the Merci Retriever as its predicate device (510(k) Number K072718). Rather than rely on a single retrieval device, Penumbra offered a system of devices that utilized aspiration as the primary mechanism for revascularization (Figure 2). In this technique, a reperfusion catheter was advanced to the face of the clot, followed by a separator passed through the reperfusion catheter. Reperfusion was achieved by debulking the clot with the separator as continuous aspiration was applied via a pump through the reperfusion catheter. If this method was unsuccessful, direct mechanical retrieval using a thrombus removal ring was attempted (20).

In line with the standard set by the Merci Retriever, the efficacy of the Penumbra System was demonstrated through a single-arm prospective trial (Penumbra
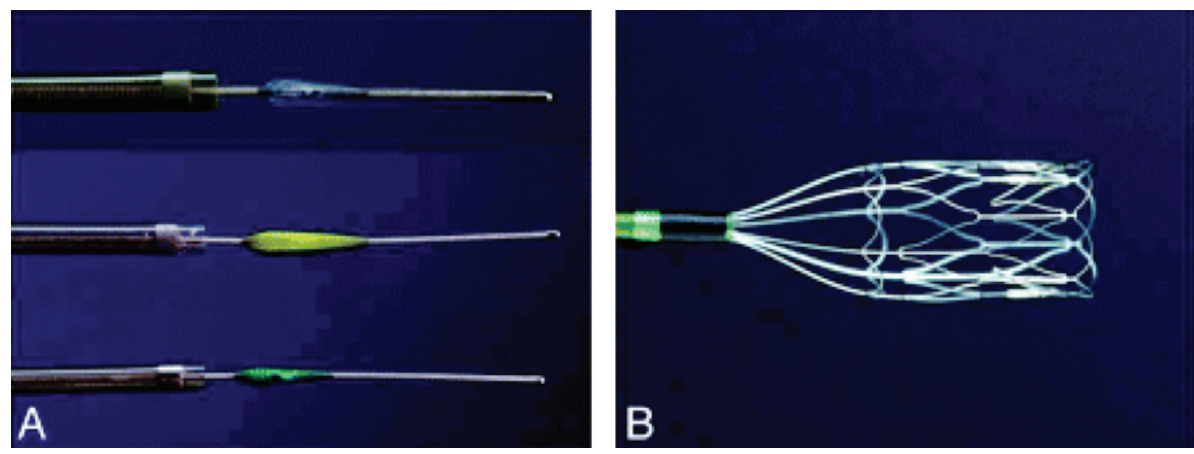

Figure 2. The original Penumbra System. A. Aspiration catheters and separators. B. Thrombus removal ring. Reproduced from Bose et al. "The Penumbra System: a mechanical device for the treatment of acute stroke due to thromboembolism" published in the American Journal of Neuroradiology 2008. Reprinted with permission. 
Pivotal Stroke Trial, 2009) in 125 patients presenting within 8 hours of stroke onset (21). Successful revascularization (TIMI 2 or 3 flow at the site of primary occlusion) was achieved in $82 \%$ of cases, compared to $69 \%$ in Multi-MERCI, however clinical outcomes remained poor with only $25 \%$ achieving a 90-day $\mathrm{mRS} \leq 2$. Mortality was also high (33\%), and complications occurred in $12.8 \%$ of patients. It is also important to note that the Penumbra Pivotal Stroke Trial used a less stringent definition for recanalization success when compared to the Merci trials, looking only at flow across the primary site of occlusion as opposed to flow in all treatable vessels (which extended to the M2 MCA for anterior LVOs and the basilar artery for posterior LVOs).

Though underwhelming, these results deemed the Penumbra System a reasonable alternative to the Merci Retriever, and would set the stage for the development of subsequent devices dedicated to aspiration thrombectomy.

\section{THE STENT RETRIEVER}

Perhaps as a result of the poor outcomes and recanalization rates reported in the Merci and Penumbra trials, interest in the development of effective clot retrieval devices persisted throughout the mid-to-late 2000s. Self-expanding stents, which at the time were cleared for the treatment of cerebral aneurysms and intracranial atherosclerotic disease, had begun to be used off-label with some success in recanalizing occluded vessels (22). However, permanent stent implantation came with major disadvantages that were especially concerning in the setting of ischemic stroke, including the need for long term platelet inhibition.

In an interesting display of off-label creativity, some neurointerventionists began to circumvent the risks of stent implantation by using partially deployed stents to achieve a "temporary endovascular bypass" in cases of thrombotic occlusion (23). In this technique, a stent was delivered across the site of occlusion and partially unconstrained, circumferentially displacing the clot and temporarily restoring flow. Antiplatelet medication was then infused through the guide catheter, and the stent was resheathed after about 20 minutes. As the temporary bypass was left in place, flow restoration was thought to facilitate thrombolysis via the dissipation of prothombotic factors within the clot, mechanical disruption of the thrombus, and increased penetration of antiplatelet or thrombolytic medication (23).

Though investigations into temporary bypass never expanded beyond small case series, the concept of clot lysis by flow restoration spawned the development of novel retrievable stents, which were attached to push-wires that allowed the device to be fully deployed, resheathed, and subsequently removed (Figure 3). In an unexpected turn of events, early testing in animal models showed that flow restoration alone was not able to effectively dissolve thrombi, but that these devices were highly effective at mechanical clot retrieval (24).

Thus the "stent retriever" emerged as a new category of thrombectomy devices, first produced in the form of the Solitaire FR (Micro Therapeutics Inc., Irvine, CA), which was followed soon after by the Trevo Retriever (Concentric Medical, Mountainview, CA). After a series of promising early experiences (25-28), the effort to attain FDA clearance for these devices would yield the first ever 


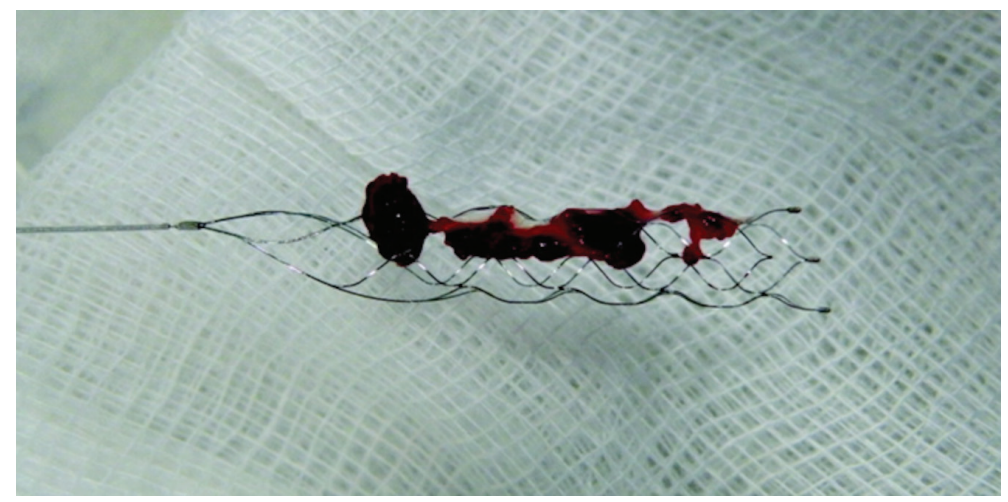

Figure 3. Solitaire FR after clot retrieval. Adapted from Castaño et al. "Mechanical Thrombectomy With the Solitaire AB Device in Large Artery Occlusions of the Anterior Circulation" published in Stroke 2010. Reprinted with permission.

head-to-head RCTs comparing two techniques for acute endovascular stroke intervention, which were published simultaneously in October 2012.

The SWIFT Trial was first to begin enrollment in February 2010, and was designed as a randomized, parallel-group, non-inferiority trial comparing the Solitaire FR to the Merci Retriever in patients harboring angiographically confirmed occlusions with moderate to severe neurological deficits within eight hours of symptom onset (29). The study randomized 103 patients, and the primary endpoint was TIMI scale 2 or 3 flow in all treatable vessels without symptomatic intracranial hemorrhage, which was adjudicated by an masked independent core lab. If the primary endpoint was not achieved following 3 passes with the assigned device, the case was categorized as failure. In this trial, Solitaire vastly outperformed the Merci Retriever, and a prespecified efficacy stopping rule triggered an early halt. The primary efficacy endpoint was reached in $61 \%$ of Solitaire group vs. $24 \%$ of the Merci group $\left(p_{\text {superiority }}=0.0001\right)$. Clinically, SWIFT defined "good neurologic outcome" as any one of the following: an mRS $<2$ at 90 days, an unchanged $\mathrm{mRS}$ if the patient's pre-stroke mRS was greater than 2, or an NIHSS score improvement of 10 points or more. Solitaire achieved superior results with regard to this clinical metric ( $58 \%$ vs. $33 \%$; p superiority $=0.02$ ), and also resulted in lower 90 -day mortality ( $17 \%$ vs. $38 \%$; $p_{\text {superiority }}=0.02$ ). The rate of $\mathrm{mRS} \leq 2$ outcomes, however, did not differ between groups.

As determined by the core lab, three or fewer passes with the assigned device resulted in TIMI 2 or 3 recanalization of all treatable vessels in $69 \%$ patients treated with Solitaire, and only $30 \%$ of those treated with the Merci Retriever $(p<0.0001)$. Though recanalization rates in both groups were lower than those that had been published in previous studies, this difference was attributed to the more rigorous core lab design of SWIFT. When assessed by the treating sites, successful recanalization rates of $83 \%$ and $48 \%$ were reported in the Solitaire and Merci groups respectively, and rose to $89 \%$ and $67 \%$ following rescue therapy.

The TREVO 2 trial was also a randomized non-inferiority trial, this time comparing the Trevo stent retriever to the Merci Retriever (30). Inclusion criteria were similar to those utilized in SWIFT, the most significant difference being that TREVO 2 only included patients with no significant pre-stroke deficits $(\mathrm{mRS} \leq 1)$. 
In contrast to the SWIFT trial, TREVO 2 used reperfusion alone (as opposed to reperfusion without hemorrhage) as the primary endpoint. Additionally, up to 6 passes (as opposed to 3) were allowed with the assigned device before treatment was considered a failure. The core lab adjudicating angiographic outcomes in TREVO 2 was unmasked, and reperfusion was graded on the more modern Thrombolysis in Cerebral Infarction (TICI) scale, using the liberal threshold of $\mathrm{TICI} \geq 2 \mathrm{a}$ to define success (31).

One hundred seventy-eight patients were randomized, and final analysis showed once again that the stent retriever group outperformed the Merci group, achieving the primary endpoint in $86 \%$ vs. $60 \%$ of cases $\left(p_{\text {superiority }}<0.0001\right.$ ) without a significant difference in procedure-related adverse events. Unlike in SWIFT, the stent retriever group in TREVO 2 also achieved higher rates of good outcome at 90 -days ( $40 \%$ vs. $22 \%$; $p=0.013$ ).

While direct comparison of these trials is complicated by their use of different outcome measures, each clearly established the superiority of stent retrievers over the Merci Retriever. These devices would go on to serve as predicates for the proliferation of stent retrievers that have entered common use today. However, before stent retrievers could become the dominant thrombectomy devices in use, doubt would be cast over the entire field of endovascular stroke intervention following a series of negative RCTs published in 2013.

\section{THE FAILURES OF 2013}

Attributable in part to the low threshold for device clearance that gave rise to first generation of thrombectomy technology, the field had progressed for more than a decade without conducting a large RCT comparing endovascular stroke intervention to standard medical management. This would change in 2013 with the simultaneous publication of MR RESCUE, IMS III, and SYNTHESIS, all of which failed to show a benefit of ESI.

MR RESCUE was completed over an 8-year period, and compared ESI using the Merci Retriever or Penumbra System to standard medical care in 118 patients presenting with angiographically confirmed ICA or MCA occlusions and NIHSS $\geq 6$ symptom severity within eight hours of stroke onset (32). There was no significant difference in clinical outcomes between groups. Stent retrievers were not tested in this study, which may in part explain why reperfusion scores were poor in the ESI group ( $67 \% \mathrm{TICI} \geq 2 \mathrm{a}$, and $27 \% \mathrm{TICI} \geq 2 \mathrm{~b}$ ).

IMS III was the largest of the three trials and compared ESI plus bridging IV thrombolysis (IVT) (stopped at 40-minutes) to IVT alone in 656 patients with stroke onset occurring less than 5 hours prior to the start of the procedure (33). The ESI group in this study consisted of a heterogeneous mix of devices and techniques chosen by the interventionalist, including thrombectomy with the Merci retriever, Penumbra System or Solitaire FR, and endovascular delivery of t-PA. When this trial commenced in 2004, computed tomography (CT) angiography was not in widespread use, and thus patients were included on the basis of NIHSS $\geq 10$ symptom severity. A later protocol modification allowed for the inclusion of patients with NIHSS 8 or 9 symptoms if an occlusion was confirmed using CT angiography. The trial was terminated due to futility when interim analysis showed 
no clinical benefit of ESI. Stent retrievers were used in only 3\% of cases, and reperfusion scores in the ESI group were once again lower than those reported in TREVO 2.

SYNTHESIS Expansion was an Italian trial that compared ESI to IVT alone in 362 patients presenting within 4.5 hours of stroke symptom onset, but did not use either CT angiography or NIHSS severity as a criteria for inclusion (34). Both mechanical thrombectomy devices and IA thrombolysis were allowed, and while this trial did include a higher percentage of stent retriever cases (13\%), more than two-thirds of patients in the ESI group (69\%) were treated with IA thrombolysis alone. There was no difference in 90-day $\mathrm{mRS} \leq 1$ outcomes, and recanalization rates were not reported.

The failure of these three trials dealt a blow to the field of endovascular stroke therapy, but more importantly they carried with them a number of important lessons regarding patient selection, workflow, and device selection that would influence the design of future stroke trials. Two years after these negative RCTs, a series of positive ESI trials completely changed the landscape of stroke intervention.

\section{THE SUCCESSES OF 2015}

Exhaustive reviews of the major 2015 RCTs are available elsewhere in the literature, and, as the focus of this chapter is on the evolution of thrombectomy devices themselves, they will be discussed here only briefly. MR CLEAN was the first positive trial to publish out of the Netherlands in January 2015, and compared ESI to standard therapy in 500 patients who presented with angiographically confirmed anterior circulation LVOs within six hours of symptom onset (35). Stent retrievers were used in $81.5 \%$ of patients in the ESI group, and final analysis showed an absolute difference of $13.5 \%$ (95\% CI, 5.9 to 21.2 ) in the rate of functional independence $(\mathrm{mRS} \leq 2)$ in favor of endovascular intervention. The ESI group demonstrated a shift towards better outcomes across all mRS categories, and there was no significant difference between groups with regard to mortality or hemorrhage.

These positive results prompted early interim analysis in seven other ongoing thrombectomy trials at the time, and ultimately led to early termination of each of them as a result of either positive outcomes or loss of clinical equipoise. By the end of 2015, four additional trials demonstrating the benefit of ESI over standard therapy would be published (summarized in Table 2) (36-39). Results from these trials would prompt multiple standard-setting organizations around the world to update their guidelines to reflect ESI as the standard of care for select patients presenting with acute LVO stroke (40-42). The next year saw the publication of three additional RCTs, one of which showed a clinical benefit of ESI with bridging IVT over IVT alone (43), while the other two were terminated before reaching sufficient power to show statistical significance (Table 2) $(44,45)$.

Through careful patient selection, efficient thrombectomy workflows, and utilization of stent-retriever devices, the 2015 trials succeeded in establishing thrombectomy as the standard of care for select LVO patients. Further studies since that time have extended the treatment window of certain patients as far out as 24-hours after symptom onset (46-48). As of 2017 however, there was still one popular method for thrombectomy that remained untested by randomized clinical trial. 


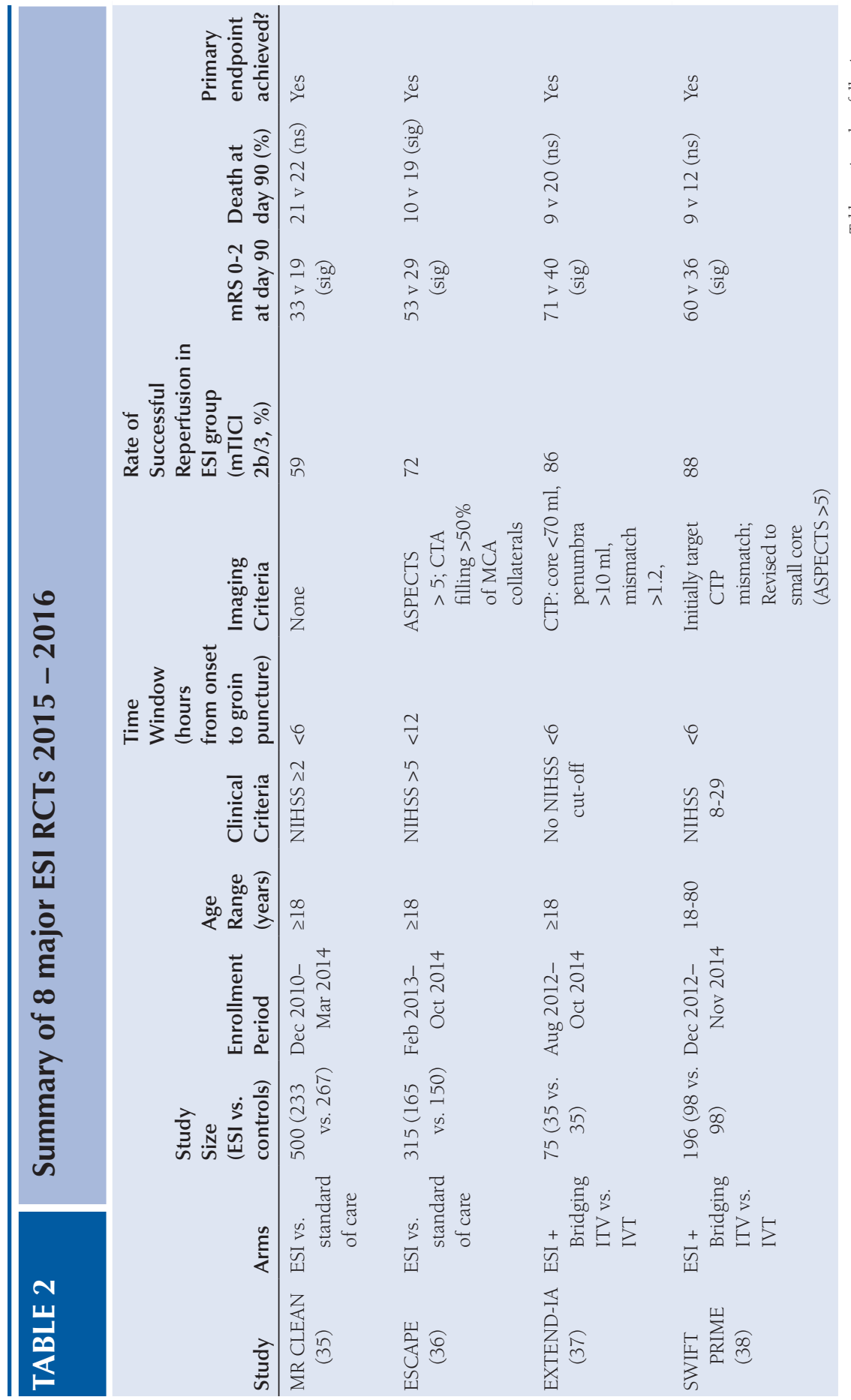




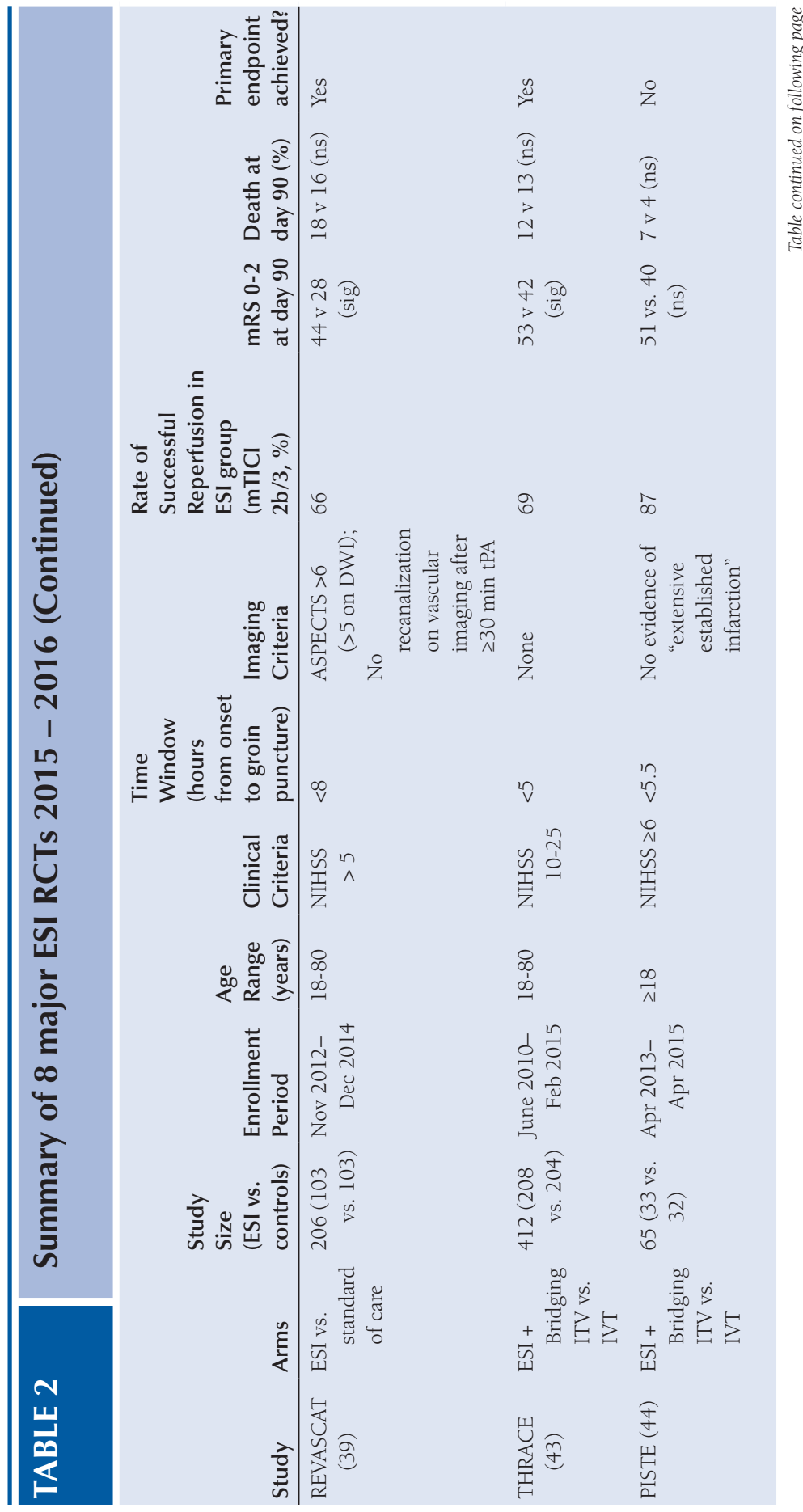




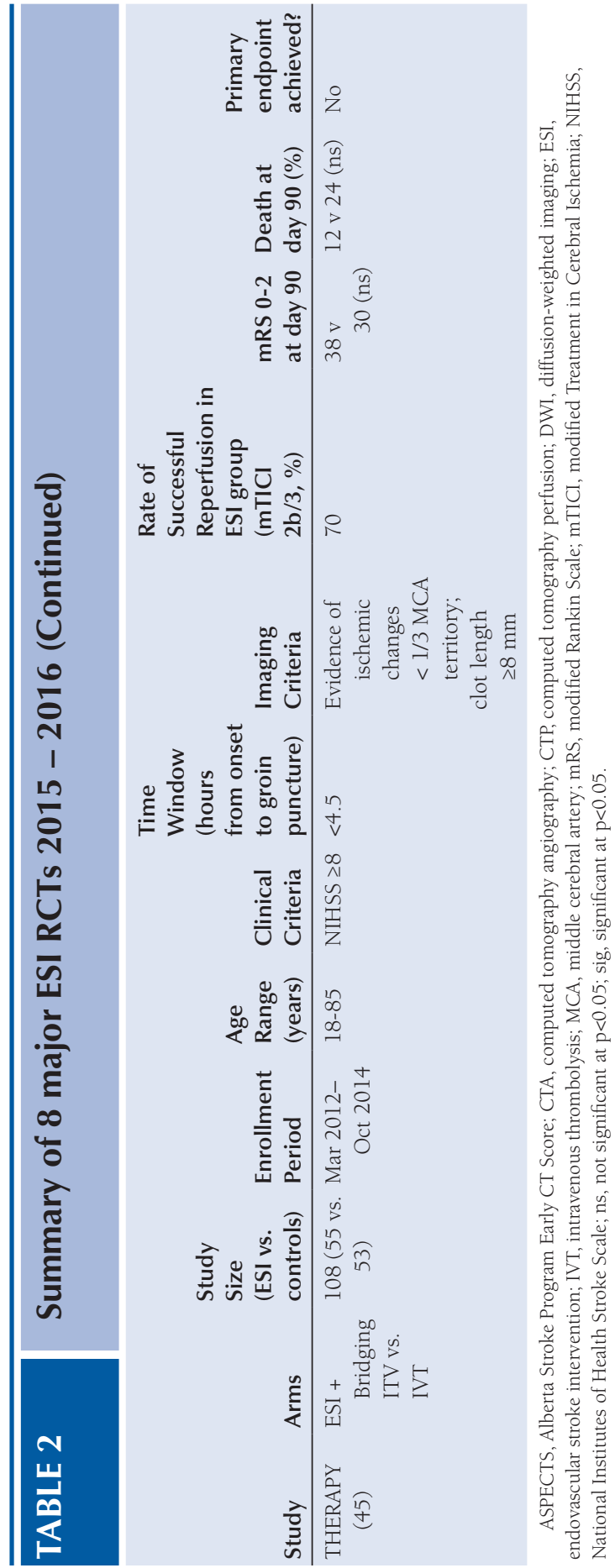




\section{DIRECT ASPIRATION}

In each of the pivotal RCTs that established the benefit of mechanical thrombectomy, stent retrievers were utilized as the device of choice. Alongside stent retrievers, however, clot retrieval through aspiration alone had gradually begun to rise as an alternative technique. One technique in particular, known as a direct aspiration first pass technique (ADAPT), had drawn considerable attention even before the pivotal stent retriever trials.

In 2014, the single arm ADAPT FAST study showed that utilizing direct aspiration though a large bore aspiration catheter as a first pass technique in 98 patients yielded similar outcomes to those reported by stent retriever studies at the time (49). In the ADAPT technique, stent retrievers are used only as a rescue device in the event that contact aspiration failed after 3 passes. Aspiration alone was successful in achieving revascularization (TICI 2 b or 3 ) in $78 \%$ of cases, and the additional use of rescue stent retrievers improved that rate to $95 \%$. Good functional outcome (90-day mRS $\leq 2$ ) was achieved in $40 \%$ of patients. As of 2015 , however, the question remained: Was ADAPT as effective as stent retriever techniques?

This question would be answered by two RCTs, both of which conducted head-to-head comparisons of ADAPT vs. stent retrievers in patients with acute ischemic stroke. The first to report results was ASTER (Contact Aspiration versus Stent Retriever for Successful Revascularization), which was published in 2017 (50). Designed to demonstrate superiority of ADAPT over stent retrievers in achieving successful reperfusion, ASTER was conducted in France and enrolled a total of 381 patients with anterior circulation LVO stroke within six hours of symptom onset.

An intention-to-treat analysis revealed that rates of successful reperfusiondefined as a modified Treatment in Cerebral Ischemia (mTICI) score $\geq 2 b$ - were not significantly different when comparing the ADAPT arm to the first-line stent retriever arm ( $83.1 \%$ vs. $85.4 \% ; p=0.53)$. Secondary analysis showed that rates of $\mathrm{mTICI} \geq 2 \mathrm{c}$ and $\mathrm{mTICI} 3$ reperfusion were likewise nondifferent between the groups and neither were rates of functional independence at 90 days ( $\mathrm{mRS} \leq 2 \mathrm{~b}$ $45.3 \%$ vs. $50.0 \%$; $\mathrm{p}=0.38$ ). Aspiration alone achieved successful reperfusion in $63 \%$ of cases, which was lower than those reported in ADAPT FAST, but nonetheless comparable to those achieved by first-line therapy in ASTER's stent retriever $\operatorname{arm}(\mathrm{p}=0.34)$.

In failing to meet its primary endpoint, ASTER bolstered the notion that ADAPT and first-line stent retriever techniques may yield similar outcomes. However, the study was limited both by its superiority design and by its focus on angiographic as opposed to clinical outcomes. For this reason, an additional study would be required to finally establish the noninferiority of ADAPT when comparted to first-line stent retriever techniques.

The COMPASS trial, published in 2019, fulfilled this need (51). Designed to demonstrate noninferiorty of ADAPT vs. first-line stent retriever thrombectomy with regard to 90-day functional independence ( $\mathrm{mRS} \leq 2)$, this study enrolled 270 anterior LVO patients within six hours of symptom onset. In order to mirror the majority of the patient populations in the 2015 RCTs, patients were excluded if they were found to have an Alberta Stroke Program Early CT Score (ASPECTS) of less than 7. 
COMPASS was successful in meeting its primary endpoint, and showed that functional independence at 90 days was observed in 52\% of patients in the ADAPT arm versus 50\% in the first-line stent retriever arm ( $p=0.001$ for noninferiority). Rates of $\mathrm{mTICI} \geq 2 \mathrm{~b}$ reperfusion on final angiogram were $92 \%$ and $89 \%$ respectively in the ADAPT and stent retriever arms $(\mathrm{p}=0.54)$. Aspiration alone achieved $\mathrm{mTICI} \geq 2 \mathrm{~b}$ reperfusion in $83 \%$ of patients, compared to $81 \%$ in the stent retriever group $(\mathrm{p}=0.75)$.

The results of COMPASS and ASTER provided Level 1 data that ADAPT is non-inferior to using stent retrievers alone for the treatment of select patients with acute large vessel ischemic stroke, a fact which as of 2021 is reflected in both American and European guidelines $(51,52)$. Investigation persists in search of indications that render one technique superior to the other, and while observational data suggests that ADAPT may yield benefits in terms of earlier reperfusion times and greater cost effectiveness, it is also possible that a proceduralist's comfort with a given technique is a greater predictor of outcome than the particular technique in question (53). Regardless of these narrow distinctions, the demonstrated equivalence of ADAPT and stent retriever techniques has led to a flourishing of device innovation that is of interest to neurointerventionalists today.

\section{CURRENT DIRECTIONS}

In the years since the landmark thrombectomy trials, there has been a proliferation of devices and techniques aimed at maximizing rates of safe, successful reperfusion while minimizing the number of passes required. Several new stent retrievers have come to market, though to date none have been compared directly to one another in a head-to-head RCT. Similar to the early days of Merci and the Penumbra System, the safety and efficacy of these devices is based largely on uncontrolled single-armstudies (54-59), with the exception of 3D Revascularization Device (Penumbra Inc., Alameda, CA), which underwent a successful noninferiority RCT using aspiration thrombectomy as the control group (60). Current interest in the field of stent retriever design has included the development of interlinked adjustable nitinol cages to allow thrombus capture, as well as the production of smaller stent retrievers that can safely be used in small distal vessels $(61,62)$.

With regard to aspiration thrombectomy, the general goal has been to produce the largest possible aspiration catheter that can be safely navigated within the intracranial vasculature. As opposed to the 0.054" lumen aspiration catheters evaluated in the original Penumbra Pivotal Stroke Trial, catheters as large as 0.072 " are now in regular use. Retrospective studies have reported increased rates of successful reperfusion (mTICI 2b) at first pass when using larger 0.68 " aspiration catheters compared to 0.060", as well as an independent association between larger lumen size (0.070" vs. 0.055") and excellent reperfusion outcomes $(63,64)$.

Recently, the limits of large bore aspiration have been pushed even further, as early experiences have been published reporting the safe use of 0.088 " lumen aspiration catheters to perform MCA thrombectomies (Figure 4) (65). Other 0.088 " aspiration catheters are currently undergoing benchtop testing (66), and 


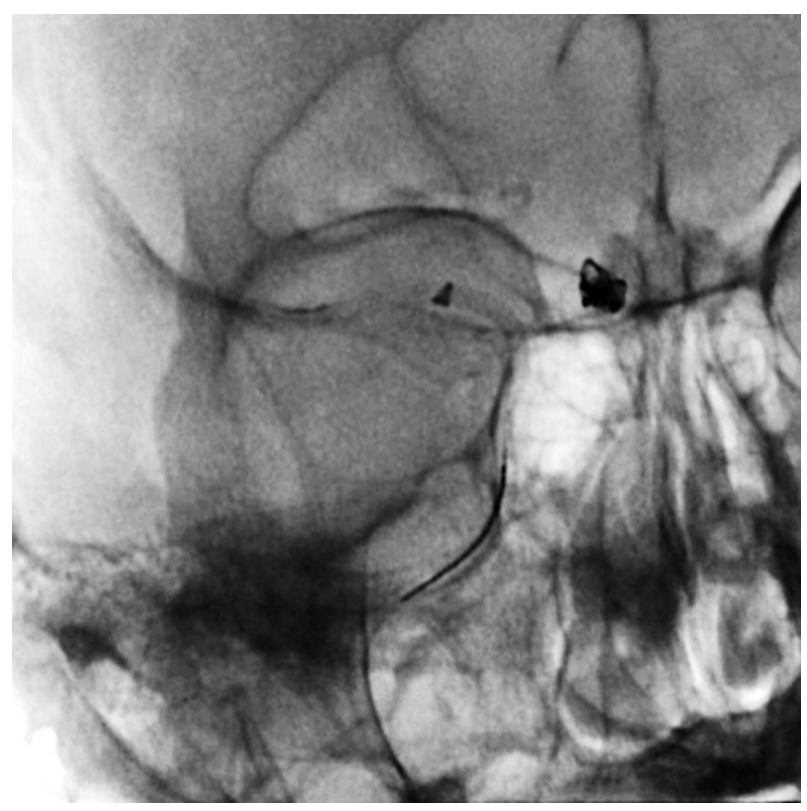

Figure 4. An 0.088" catheter (ZOOM 88, Imperative Care, Fremont, CA) located in the M1 MCA during thrombectomy.

more exotic designs (such as the R4Q, MIVI Neuroscience, Inc., Eden Prairie, $\mathrm{MN}$ ) have been offered to increase function lumen size without increasing the outer catheter diameter (67). While it is thought that such large lumen sizes may improve recanalization rates by offering higher suction force as well as a degree of flow restriction proximal to the clot, evidence for the benefits of large bore aspiration is not unequivocal, and controlled trials will be necessary (68).

Though BCGs have been in use since the very first MERCI Trial, efforts are ongoing to produce a design that will find widespread adoption in the neurointerventional community. Studies reporting improved clinical and angiographic outcomes using BGCs extend as far back as 2014 (69), and metanalyses corroborating this benefit have been conducted in the years since (70). More recently, a large multicenter Korean registry has found that these benefits are not limited to stent retriever thrombectomy, and persisted even when an ADAPT technique was utilized (71). Benchtop testing suggest that these benefits, if present, are likely a result of improved flow reversal achieved by BGCs in comparison to conventional guide catheters, which may result in decreased clot fragmentation and fewer distal emboli (72). Despite the promise shown by recent reports, most available BGCs are limited due to their larger outer diameter, increased rigidity, and smaller relative lumen size when compared to conventional guide catheters. Current efforts in improving BGC design, such as the FlowGate2 (Stryker, Kalamazoo, MI) and Walrus (Q'apel, Fremont, CA) are aimed at overcoming these limitations.

In addition to new devices, the development of novel techniques for clot extraction utilizing different device combinations has been a major area of interest 
within the neurointerventional community. The Solumbra technique was among the first to be investigated and involves the retrieval of a stent retriever through an aspiration catheter that is simultaneously applying suction to the face of the clot (73). Despite seemingly sound mechanistic underpinnings, this technique was found to yield inferior clinical outcomes when compared to ADAPT in a 2016 retrospective study (mRS $\leq 2$ in $30.9 \%$ vs. $55.6 \%, p=0.015$ ) (74). Since that time, a series of small studies have been conducted in order to refine Solumbra, resulting in techniques such as CAPTIVE (Continuous aspiration prior to intracranial vascular embolectomy), ARTS (Aspiration (catheter)-(stent) Retriever Technique for Stroke), and SAVE (Stent retriever Assisted Vacuum-locked Extraction) (75-77). To date, ADAPT is the only alternative thrombectomy technique to be evaluated in the setting of an RCT, and this standard will need to be met once again before any new technique should be adopted into routine practice.

\section{CONCLUSION}

The evolution of devices and techniques in endovascular stroke therapy reveals how new therapies are developed, evaluated, and adopted. Among the most important lessons is the observation that liberal standards for FDA device clearance enabled the development of first-generation thrombectomy devices, but also resulted in a dearth of high quality RCTs that culminated in the failures of 2013. After the positive results of PROACT II in 1999, more than fifteen years would pass before another trial demonstrated superiority of EVSI over standard therapy. Although that period of time was marked by a series of devices that added little to the effective treatment of stroke, each of those steps led to the therapeutic breakthrough in 2015. Suddenly, exciting new devices entered the world of stroke intervention. But similar to the early days of thrombectomy, the current number of available devices far outstrips the number of high-quality RCTs evaluating their safety and efficacy. If further progress is to be made in improving stroke outcomes, more rigorous investigation must be undertaken to identify the next significant development in endovascular stroke therapy.

Conflict of interest: The authors declare no potential conflicts of interest with respect to research, authorship and/or publication of this article.

Copyright and permission statement: The authors confirm that the materials included in this chapter do not violate copyright laws. Where relevant, appropriate permissions have been obtained from the original copyright holder(s), and all original sources have been appropriately acknowledged or referenced.

\section{REFERENCES}

1. Zeumer H, Hacke W, Ringelstein EB. Local intraarterial thrombolysis in vertebrobasilar thromboembolic disease. AJNR Am J Neuroradiol. 1983;4(3):401-4.

2. Tissue plasminogen activator for acute ischemic stroke. N Engl J Med. 1995;333(24):1581-7. https:// doi.org/10.1056/NEJM199512143332401 
3. Clark WM, Wissman S, Albers GW, Jhamandas JH, Madden KP, Hamilton S. Recombinant tissuetype plasminogen activator (Alteplase) for ischemic stroke 3 to 5 hours after symptom onset. The ATLANTIS Study: a randomized controlled trial. Alteplase Thrombolysis for Acute Noninterventional Therapy in Ischemic Stroke. JAMA. 1999 Dec 1;282(21):2019-26. doi: 10.1001/jama.282.21.2019. PMID: 10591384.

4. Donnan GA, Davis SM, Chambers BR, Gates PC, Hankey GJ, McNeil JJ, et al. Streptokinase for acute ischemic stroke with relationship to time of administration. Jama. 1996;276(12):961-6. https://doi. org/10.1001/jama.1996.03540120039031

5. Group MASTES. Thrombolytic therapy with streptokinase in acute ischemic stroke. N Engl J Med. 1996;335(3):145-50. https://doi.org/10.1056/NEJM199607183350301

6. Hacke W, Kaste M, Fieschi C, Toni D, Lesaffre E, Von Kummer R, et al. Intravenous thrombolysis with recombinant tissue plasminogen activator for acute hemispheric stroke: the European Cooperative Acute Stroke Study (ECASS). Jama. 1995;274(13):1017-25. https://doi.org/10.1001/ jama.1995.03530130023023

7. Hacke W, Kaste M, Fieschi C, Von Kummer R, Davalos A, Meier D, et al. Randomised doubleblind placebo-controlled trial of thrombolytic therapy with intravenous alteplase in acute ischaemic stroke (ECASS II). Lancet. 1998;352(9136):1245-51. https://doi.org/10.1016/ S0140-6736(98)08020-9

8. Trial-Italy MAS. Randomised controlled trial of streptokinase, aspirin, and combination of both in treatment of acute ischaemic stroke. Lancet. 1995;346(8989):1509-14. https://doi.org/10.1016/ S0140-6736(95)92049-8

9. Jauch EC, Saver JL, Adams HP, Bruno A, Connors JJ, Demaerschalk BM, et al. Guidelines for the Early Management of Patients With Acute Ischemic Stroke. Stroke. 2013;44(3):870-947. https://doi. org/10.1161/STR.0b013e318284056a

10. FDA PLA Supplement 96-0350 March 19, 1996 for tissue plasminogen activator (tPA; ActivaseR) with the proposed additional indication of: 'Activase is indicated for the management of acute ischemic stroke in adults for improving functional outcome and neurological recovery and reducing the incidence of disability associated with stroke'. TTATTS, p 68. https://www.accessdata.fda.gov/ drugsatfda_docs/nda/96/altegen061896r2.pdf

11. Smith WS, Furlan AJ. Brief History of Endovascular Acute Ischemic Stroke Treatment. Stroke. 2016;47(2):e23-e6. https://doi.org/10.1161/STROKEAHA.115.010863

12. del Zoppo GJ, Higashida RT, Furlan AJ, Pessin MS, Rowley HA, Gent M. PROACT: a phase II randomized trial of recombinant pro-urokinase by direct arterial delivery in acute middle cerebral artery stroke. PROACT Investigators. Prolyse in Acute Cerebral Thromboembolism. Stroke. 1998;29(1): 4-11. https://doi.org/10.1161/01.STR.29.1.4

13. Furlan A, Higashida R, Wechsler L, Gent M, Rowley H, Kase C, et al. Intra-arterial prourokinase for acute ischemic stroke. The PROACT II study: a randomized controlled trial. Prolyse in Acute Cerebral Thromboembolism. Jama. 1999;282(21):2003-11. https://doi.org/10.1001/jama.282.21.2003

14. Lee M, Hong K-S, Saver JL. Efficacy of Intra-Arterial Fibrinolysis for Acute Ischemic Stroke. Stroke. 2010;41(5):932-7. https://doi.org/10.1161/STROKEAHA.109.574335

15. Leary MC, Saver JL, Gobin YP, Jahan R, Duckwiler GR, Vinuela F, et al. Beyond tissue plasminogen activator: Mechanical intervention in acute stroke. Ann Emerg Med. 2003;41(6):838-46. https://doi. org/10.1067/mem.2003.194

16. Felten RP, Ogden NRP, Peña C, Provost MC, Schlosser MJ, Witten CM. The Food and Drug Administration Medical Device Review Process. Stroke. 2005;36(2):404-6. https://doi.org/10.1161/01. STR.0000153063.54972.91

17. Smith WS, Sung G, Starkman S, Saver JL, Kidwell CS, Gobin YP, et al. Safety and Efficacy of Mechanical Embolectomy in Acute Ischemic Stroke. Stroke. 2005;36(7):1432-8. https://doi.org/10.1161/01. STR.0000171066.25248.1d

18. Gobin YP, Starkman S, Duckwiler GR, Grobelny T, Kidwell CS, Jahan R, et al. MERCI 1. Stroke. 2004;35(12):2848-54. https://doi.org/10.1161/01.STR.0000147718.12954.60

19. Smith WS. Safety of mechanical thrombectomy and intravenous tissue plasminogen activator in acute ischemic stroke. Results of the multi Mechanical Embolus Removal in Cerebral Ischemia (MERCI) trial, part I. AJNR Am J Neuroradiol. 2006;27(6):1177-82. 
20. Bose A, Henkes H, Alfke K, Reith W, Mayer TE, Berlis A, et al. The Penumbra System: a mechanical device for the treatment of acute stroke due to thromboembolism. AJNR Am J Neuroradiol. 2008;29(7):1409-13. https://doi.org/10.3174/ajnr.Al110

21. The Penumbra Pivotal Stroke Trial. Stroke. 2009;40(8):2761-8. https://doi.org/10.1161/ STROKEAHA. 108.544957

22. Levy EI, Siddiqui AH, Crumlish A, Snyder KV, Hauck EF, Fiorella DJ, et al. First Food and Drug Administration-Approved Prospective Trial of Primary Intracranial Stenting for Acute Stroke. Stroke. 2009;40(11):3552-6. https://doi.org/10.1161/STROKEAHA.109.561274

23. Kelly ME, Furlan AJ, Fiorella D. Recanalization of an acute middle cerebral artery occlusion using a self-expanding, reconstrainable, intracranial microstent as a temporary endovascular bypass. Stroke. 2008;39(6):1770-3. https://doi.org/10.1161/STROKEAHA.107.506212

24. Shrivastava S, Cam A, Slee E. A novel device for the revascularization in acute ischemic stroke patients. Interv Neuroradiol. 2010;16(3):306-8. https://doi.org/10.1177/159101991001600313

25. Castaño C, Dorado L, Guerrero C, Millán M, Gomis M, Ossa NPdl, et al. Mechanical Thrombectomy With the Solitaire AB Device in Large Artery Occlusions of the Anterior Circulation. Stroke. 2010;41(8):1836-40. https://doi.org/10.1161/STROKEAHA.110.584904

26. Miteff F, Faulder KC, Goh ACC, Steinfort BS, Sue C, Harrington TJ. Mechanical Thrombectomy with a Self-Expanding Retrievable Intracranial Stent (Solitaire AB): Experience in 26 Patients with Acute Cerebral Artery Occlusion. Am J Neuroradiol. 2011;32(6):1078-81. https://doi.org/10.3174/ajnr.A2447

27. Mendonça N, Flores A, Pagola J, Rubiera M, Rodríguez-Luna D, De Miquel MA, et al. Trevo System: Single-Center Experience with a Novel Mechanical Thrombectomy Device. J Neuroimaging. 2013;23(1):7-11. https://doi.org/10.1111/j.1552-6569.2011.00666.x

28. Román LS, Obach V, Blasco J, Macho J, Lopez A, Urra X, et al. Single-Center Experience of Cerebral Artery Thrombectomy Using the TREVO Device in 60 Patients With Acute Ischemic Stroke. Stroke. 2012;43(6):1657-9. https://doi.org/10.1161/STROKEAHA.111.640011

29. Saver JL, Jahan R, Levy EI, Jovin TG, Baxter B, Nogueira RG, et al. Solitaire flow restoration device versus the Merci Retriever in patients with acute ischaemic stroke (SWIFT): a randomised, parallel-group, noninferiority trial. Lancet. 2012;380(9849):1241-9. https://doi.org/10.1016/S0140-6736(12)61384-1

30. Nogueira RG, Lutsep HL, Gupta R, Jovin TG, Albers GW, Walker GA, et al. Trevo versus Merci retrievers for thrombectomy revascularisation of large vessel occlusions in acute ischaemic stroke (TREVO 2): a randomised trial. Lancet. 2012;380(9849):1231-40. https://doi.org/10.1016/S0140-6736(12)61299-9

31. Higashida RT, Furlan AJ. Trial Design and Reporting Standards for Intra-Arterial Cerebral Thrombolysis for Acute Ischemic Stroke. Stroke. 2003;34(8):e109-e37. https://doi.org/10.1161/01. STR.0000082721.62796.09

32. Kidwell CS, Jahan R, Gornbein J, Alger JR, Nenov V, Ajani Z, et al. A trial of imaging selection and endovascular treatment for ischemic stroke. N Engl J Med. 2013;368(10):914-23. https://doi. org/10.1056/NEJMoal212793

33. Broderick JP, Palesch YY, Demchuk AM, Yeatts SD, Khatri P, Hill MD, et al. Endovascular therapy after intravenous t-PA versus t-PA alone for stroke. N Engl J Med. 2013;368(10):893-903. https://doi. org/10.1056/NEJMoal214300

34. Ciccone A, Valvassori L, Nichelatti M, Sgoifo A, Ponzio M, Sterzi R, et al. Endovascular treatment for acute ischemic stroke. N Engl J Med. 2013;368(10):904-13. https://doi.org/10.1056/NEJMoal213701

35. Berkhemer OA, Fransen PS, Beumer D, van den Berg LA, Lingsma HF, Yoo AJ, et al. A randomized trial of intraarterial treatment for acute ischemic stroke. N Engl J Med. 2015;372(1):11-20. https:// doi.org/10.1056/NEJMoal411587

36. Goyal M, Demchuk AM, Menon BK, Eesa M, Rempel JL, Thornton J, et al. Randomized assessment of rapid endovascular treatment of ischemic stroke. N Engl J Med. 2015;372(11):1019-30. https://doi. org/10.1056/NEJMoal414905

37. Campbell BC, Mitchell PJ, Kleinig TJ, Dewey HM, Churilov L, Yassi N, et al. Endovascular therapy for ischemic stroke with perfusion-imaging selection. N Engl J Med. 2015;372(11):1009-18. https://doi. org/10.1056/NEJMoal414792

38. Saver JL, Goyal M, Bonafe A, Diener HC, Levy EI, Pereira VM, et al. Stent-retriever thrombectomy after intravenous t-PA vs. t-PA alone in stroke. N Engl J Med. 2015;372(24):2285-95. https://doi. org/10.1056/NEJMoal415061 
39. Jovin TG, Chamorro A, Cobo E, de Miquel MA, Molina CA, Rovira A, et al. Thrombectomy within 8 hours after symptom onset in ischemic stroke. N Engl J Med. 2015;372(24):2296-306. https://doi. org/10.1056/NEJMoal503780

40. Powers WJ, Derdeyn CP, Biller J, Coffey CS, Hoh BL, Jauch EC, et al. 2015 American Heart Association/American Stroke Association Focused Update of the 2013 Guidelines for the Early Management of Patients With Acute Ischemic Stroke Regarding Endovascular Treatment: A Guideline for Healthcare Professionals From the American Heart Association/American Stroke Association. Stroke. 2015;46(10):3020-35. https://doi.org/10.1161/STR.0000000000000074

41. Casaubon LK, Boulanger JM, Blacquiere D, Boucher S, Brown K, Goddard T, et al. Canadian Stroke Best Practice Recommendations: Hyperacute Stroke Care Guidelines, Update 2015. Int J Stroke. 2015;10(6):924-40. https://doi.org/10.1111/ijs.12551

42. Wahlgren N, Moreira T, Michel P, Steiner T, Jansen O, Cognard C, et al. Mechanical thrombectomy in acute ischemic stroke: Consensus statement by ESO-Karolinska Stroke Update 2014/2015, supported by ESO, ESMINT, ESNR and EAN. Int J Stroke. 2016;11(1):134-47. https://doi. org/10.1177/1747493015609778

43. Bracard S, Ducrocq X, Mas JL, Soudant M, Oppenheim C, Moulin T, et al. Mechanical thrombectomy after intravenous alteplase versus alteplase alone after stroke (THRACE): a randomised controlled trial. Lancet Neurol. 2016;15(11):1138-47. https://doi.org/10.1016/S1474-4422(16)30177-6

44. Muir KW, Ford GA, Messow CM, Ford I, Murray A, Clifton A, et al. Endovascular therapy for acute ischaemic stroke: the Pragmatic Ischaemic Stroke Thrombectomy Evaluation (PISTE) randomised, controlled trial. J Neurol Neurosurg Psychiatry. 2017;88(1):38-44. https://doi.org/10.1136/jnnp-2016-314117

45. Mocco J, Zaidat OO, von Kummer R, Yoo AJ, Gupta R, Lopes D, et al. Aspiration Thrombectomy After Intravenous Alteplase Versus Intravenous Alteplase Alone. Stroke. 2016;47(9):2331-8. https://doi. org/10.1161/STROKEAHA.116.013372

46. Nogueira RG, Jadhav AP, Haussen DC, Bonafe A, Budzik RF, Bhuva P, et al. Thrombectomy 6 to 24 Hours after Stroke with a Mismatch between Deficit and Infarct. N Engl J Med. 2017;378(1):11-21. https://doi.org/10.1056/NEJMoal706442

47. Albers GW, Marks MP, Kemp S, Christensen S, Tsai JP, Ortega-Gutierrez S, et al. Thrombectomy for Stroke at 6 to 16 Hours with Selection by Perfusion Imaging. N Engl J Med. 2018;378(8):708-18. https://doi.org/10.1056/NEJMoa1713973

48. Powers WJ, Rabinstein AA, Ackerson T, Adeoye OM, Bambakidis NC, Becker K, et al. Guidelines for the Early Management of Patients With Acute Ischemic Stroke: 2019 Update to the 2018 Guidelines for the Early Management of Acute Ischemic Stroke: A Guideline for Healthcare Professionals From the American Heart Association/American Stroke Association. Stroke. 2019;50(12):e344-e418. https://doi.org/10.1161/STR.0000000000000211

49. Turk AS, Frei D, Fiorella D, Mocco J, Baxter B, Siddiqui A, et al. ADAPT FAST study: a direct aspiration first pass technique for acute stroke thrombectomy. J Neurointerv Surg. 2014;6(4):260. https:// doi.org/10.1136/neurintsurg-2014-011125

50. Lapergue B, Blanc R, Gory B, Labreuche J, Duhamel A, Marnat G, et al. Effect of Endovascular Contact Aspiration vs Stent Retriever on Revascularization in Patients With Acute Ischemic Stroke and Large Vessel Occlusion: The ASTER Randomized Clinical Trial. JAMA. 2017;318(5):443-52. https://doi. org/10.1001/jama.2017.9644

51. Turk AS, 3rd, Siddiqui A, Fifi JT, De Leacy RA, Fiorella DJ, Gu E, et al. Aspiration thrombectomy versus stent retriever thrombectomy as first-line approach for large vessel occlusion (COMPASS): a multicentre, randomised, open label, blinded outcome, non-inferiority trial. Lancet. 2019;393(10175):9981008. https://doi.org/10.1016/S0140-6736(19)30297-1

52. Powers WJ, Rabinstein AA, Ackerson T, Adeoye OM, Bambakidis NC, Becker K, et al. 2018 Guidelines for the Early Management of Patients With Acute Ischemic Stroke: A Guideline for Healthcare Professionals From the American Heart Association/American Stroke Association. Stroke. 2018;49(3):e46-el10. https://doi.org/10.1161/STR.0000000000000163

53. Turk AS, Turner R, Spiotta A, Vargas J, Holmstedt C, Ozark S, et al. Comparison of endovascular treatment approaches for acute ischemic stroke: cost effectiveness, technical success, and clinical outcomes. J NeuroInterv Surg. 2015;7(9):666. https://doi.org/10.1136/neurintsurg-2014-011282 
54. Zaidat OO, Bozorgchami H, Ribó M, Saver JL, Mattle HP, Chapot R, et al. Primary Results of the Multicenter ARISE II Study (Analysis of Revascularization in Ischemic Stroke With EmboTrap). Stroke. 2018;49(5):1107-15. https://doi.org/10.1161/STROKEAHA.117.020125

55. Prothmann S, Schwaiger BJ, Gersing AS, Reith W, Niederstadt T, Felber A, et al. Acute Recanalization of Thrombo-Embolic Ischemic Stroke with pREset (ARTESp): the impact of occlusion time on clinical outcome of directly admitted and transferred patients. J Neurointerv Surg. 2017;9(9):817-22. https:// doi.org/10.1136/neurintsurg-2016-012556

56. Pierot L, Gauvrit JY, Costalat V, Piotin M, Mounayer C, Herbreteau D, et al. Endovascular treatment of acute ischemic stroke with ERIC device. J Neuroradiol. 2017;44(6):367-70. https://doi. org/10.1016/j.neurad.2017.06.004

57. Kaschner MG, Weiss D, Rubbert C, Lee JI, Gliem M, Jander S, et al. One-year single-center experience with the Aperio thrombectomy device in large vessel occlusion in the anterior circulation: safety, efficacy, and clinical outcome. Neurol Sci. 2019;40(7):1443-51. https://doi.org/10.1007/ s10072-019-03861-z

58. Kara B, Selcuk HH, Erbahceci Salik A, Zalov H, Yildiz O, Gul G, et al. Single-center experience with the Tigertriever device for the recanalization of large vessel occlusions in acute ischemic stroke. J Neurointerv Surg. 2019;11(5):455-9. https://doi.org/10.1136/neurintsurg-2018-014196

59. Ernst E, Papanagiotou P, Politi M, Alexandrou M, Kastrup A, Boutchakova M, et al. Safety and effectiveness of $\mathrm{CATCH}+$ as a first-line device for revascularization in the treatment of acute ischemic stroke. J Neuroradiol. 2021;48(1):5-9. https://doi.org/10.1016/j.neurad.2019.07.009

60. Nogueira RG, Frei D, Kirmani JF, Zaidat O, Lopes D, Turk AS, 3rd, et al. Safety and Efficacy of a 3-Dimensional Stent Retriever With Aspiration-Based Thrombectomy vs Aspiration-Based Thrombectomy Alone in Acute Ischemic Stroke Intervention: A Randomized Clinical Trial. JAMA Neurol. 2018;75(3):304-11. https://doi.org/10.1001/jamaneurol.2017.3967

61. Kaneko N, Komuro Y, Yokota H, Tateshima S. Stent retrievers with segmented design improve the efficacy of thrombectomy in tortuous vessels. J Neurointerv Surg. 2019;11(2):119-22. https://doi. org/10.1136/neurintsurg-2018-014061

62. Kurre W, Aguilar-Pérez M, Martinez-Moreno R, Schmid E, Bäzner H, Henkes H. Stent Retriever Thrombectomy of Small Caliber Intracranial Vessels Using pREset LITE: Safety and Efficacy. Clin Neuroradiol. 2017;27(3):351-60. https://doi.org/10.1007/s00062-016-0497-0

63. Delgado Almandoz JE, Kayan Y, Wallace AN, Tarrel RM, Fease JL, Scholz JM, et al. Larger ACE 68 aspiration catheter increases first-pass efficacy of ADAPT technique. J Neurointerv Surg. 2019;11(2):1416. https://doi.org/10.1136/neurintsurg-2018-013957

64. Marnat G, Barreau X, Detraz L, Bourcier R, Gory B, Sgreccia A, et al. First-Line Sofia Aspiration Thrombectomy Approach within the Endovascular Treatment of Ischemic Stroke Multicentric Registry: Efficacy, Safety, and Predictive Factors of Success. AJNR Am J Neuroradiol. 2019;40(6):1006-12. https://doi.org/10.3174/ajnr.A6074

65. Gershon BS, Bageac DV, Shigematsu T, Majidi S, De Leacy R. First clinical report of aspiration through a novel 0.088-inch catheter positioned in the Ml middle cerebral artery for ELVO thrombectomy. BMJ Case Rep. 2020;13(10). https://doi.org/10.1136/bcr-2020-016780

66. Fitzgerald S, Ryan D, Thornton J, Nogueira RG. Preclinical evaluation of Millipede 088 intracranial aspiration catheter in cadaver and in vitro thrombectomy models. J Neurointerv Surg. 2021;13: 447-52. https://doi.org/10.1136/neurintsurg-2020-016218

67. Long TD, Kallmes DF, Hanel R, Shigematsu T, Halaszyn AM, Wolter J, et al. Novel aspiration catheter design for acute stroke thrombectomy. J Neurointerv Surg. 2019;11(2):190-5. https://doi. org/10.1136/neurintsurg-2017-013702

68. Tonetti DA, Desai SM, Casillo S, Zussman BM, Brown MW, Jadhav AP, et al. Large-bore aspiration catheter selection does not influence reperfusion or outcome after manual aspiration thrombectomy. J Neurointerv Surg. 2019;11(7):637-40. https://doi.org/10.1136/neurintsurg-2018-014633

69. Nguyen TN, Malisch T, Castonguay AC, Gupta R, Sun CH, Martin CO, et al. Balloon guide catheter improves revascularization and clinical outcomes with the Solitaire device: analysis of the North American Solitaire Acute Stroke Registry. Stroke. 2014;45(1):141-5. https://doi.org/10.1161/ STROKEAHA.113.002407 
70. Brinjikji W, Starke RM, Murad MH, Fiorella D, Pereira VM, Goyal M, et al. Impact of balloon guide catheter on technical and clinical outcomes: a systematic review and meta-analysis. J Neurointerv Surg. 2018;10(4):335-9. https://doi.org/10.1136/neurintsurg-2017-013179

71. Baek JH, Kim BM, Kang DH, Heo JH, Nam HS, Kim YD, et al. Balloon Guide Catheter Is Beneficial in Endovascular Treatment Regardless of Mechanical Recanalization Modality. Stroke. 2019;50(6): 1490-6. https://doi.org/10.1161/STROKEAHA.118.024723

72. Chueh JY, Puri AS, Wakhloo AK, Gounis MJ. Risk of distal embolization with stent retriever thrombectomy and ADAPT. J Neurointerv Surg. 2016;8(2):197-202. https://doi.org/10.1136/ neurintsurg-2014-011491

73. Deshaies EM. Tri-axial system using the Solitaire-FR and Penumbra Aspiration Microcatheter for acute mechanical thrombectomy. J Clin Neurosci. 2013;20(9):1303-5. https://doi.org/10.1016/j. jocn.2012.10.037

74. Delgado Almandoz JE, Kayan Y, Young ML, Fease JL, Scholz JM, Milner AM, et al. Comparison of clinical outcomes in patients with acute ischemic strokes treated with mechanical thrombectomy using either Solumbra or ADAPT techniques. J Neurointerv Surg. 2016;8(11):1123-8. https://doi. org/10.1136/neurintsurg-2015-012122

75. Maus V, Behme D, Kabbasch C, Borggrefe J, Tsogkas I, Nikoubashman O, et al. Maximizing First-Pass Complete Reperfusion with SAVE. Clin Neuroradiol. 2018;28(3):327-38. https://doi.org/10.1007/ s00062-017-0566-z

76. Massari F, Henninger N, Lozano JD, Patel A, Kuhn AL, Howk M, et al. ARTS (Aspiration-Retriever Technique for Stroke): Initial clinical experience. Interv Neuroradiol. 2016;22(3):325-32. https://doi. org/10.1177/1591019916632369

77. McTaggart RA, Tung EL, Yaghi S, Cutting SM, Hemendinger M, Gale HI, et al. Continuous aspiration prior to intracranial vascular embolectomy (CAPTIVE): a technique which improves outcomes. J Neurointerv Surg. 2017;9(12):1154-9. https://doi.org/10.1136/neurintsurg-2016-012838 